\title{
The Human Glance, the Experience of Environmental Distress and the "Affordance" of Nature: Toward a Phenomenology of the Ecological Crisis
}

\author{
Vincent Blok ${ }^{1,2}$
}

Accepted: 13 August 2015/Published online: 25 August 2015

(C) The Author(s) 2015. This article is published with open access at Springerlink.com

\begin{abstract}
The problem we face today is that there is a huge gap between our ethical judgments about the ecological crisis on the one hand and our ethical behavior according to these judgments on the other. In this article, we ask to what extent a phenomenology of the ecological crisis enables us to bridge this gap and display more ethical or pro-environmental behavior. To answer this question, our point of departure is the affordance theory of the American psychologist and founding father of ecological psychology, James Gibson. There are two reasons for taking this approach. First of all, an ontological reading of Gibson's affordance theory provides a concept of nature which is non-dualistic, non-anthropocentric and eco-centric, but is not seen as an 'intrinsic value' or product of 'human valuation'. Secondly, the affordance ontology provides us with a concept of nature which in itself calls for certain action and behavior. If we indeed face a gap between ethical judgment and ethical behavior with regard to the current ecological crisis, an affordance of nature could bridge this gap. Based on our ontological reading of Gibson's affordance theory, we open a radically new perspective on the current ecological crisis and the responsibility of mankind with regard to this crisis.
\end{abstract}

Keywords Ecological crisis - Environmental ethics · Phenomenology · Affordance · James Gibson

Vincent Blok

info@vincentblok.nl

1 Social Sciences Group, Wageningen University, Hollandseweg 1, $6707 \mathrm{KN}$ Wageningen, The Netherlands

2 Faculty of Philosophy, Theology and Religious Studies, Radboud University Nijmegen, Nijmegen, The Netherlands 


\section{Introduction}

The main societal problem we face today is not that the necessity of a more sustainable economy is not recognized. Thanks to the stream of information supplied by science and politics, media and business leaders, we are becoming increasingly aware of the potentially disastrous impact of climate change and the need for a more sustainable economy. The real problem we face today is that there is a huge gap between our ethical judgments about the ecological crisis on the one hand and our ethical behavior according to these judgments on the other. In the Living Planet Report 2012, for instance, it becomes clear that humanity is using $50 \%$ more resources than the earth can provide, and that we need more than two planets to support our modern way of living by 2030. More in particular, it is acknowledged that biodiversity is still declining and that 2.7 million people around the world have to cope with water scarcity (WWF 2012). People in richer regions should reduce their resource use so that people in poorer regions can increase theirs (Friends of the Earth 2009). Although all this is widely acknowledged, hardly any sign can be found today that this 'knowledge' has resulted in significant changes in our actual behavior (PBL 2013).

In the philosophical tradition from Aristotle on, such a gap between ethical judgment and ethical behavior is explained in terms of the akrasia or impotence of people to act in accordance with reason. According to Aristotle, such a state is due to emotions or feelings which prevent rational choice, for instance our appetite for pleasure (Aristotle 1990, 1145a15ff). Can we lay the blame for people's irresponsiveness or indifference with regard to the ecological crisis on their irrationality or hedonism? As a consequence, we could explore interventions with the aim of making more reasonable choices in environmental affairs, ranging from education for sustainable development in order to increase environmental consciousness, to all kinds of policies for the restriction of industrial pollution, the preservation of natural resources or the reduction of greenhouse gas emissions.

We can also criticize this focus on 'knowledge' to promote ethical behavior. From a Levinassian perspective, we can argue that knowledge has nothing to do with ethical behavior. In Totality and Infinity, Levinas argues: "Western philosophy has most often been an ontology: a reduction of the other to the same by interposition of a middle and neutral term that ensures the comprehension of being" (Levinas 1969, 43). According to Levinas, knowledge presupposes the introduction of a middle term-concepts like 'human', 'nature' etc.—as a unifying principle in the light of which different humans for instance merge together and all appear as the same animal rationale. Levinas speaks of a reduction because the singularity or otherness of different humans is neglected in favor of their sameness as animal rationale. For this reason, Levinas argues: "The relation with Being that is enacted as ontology consists in neutralizing the existent in order to comprehend or grasp it. It is hence not a relation with the other as such but the reduction of the other to the same" (Levinas 1969, 45-46). Because of this reduction, we can grasp and understand different humans as each being an animal rationale, for instance, but this knowledge according to Levinas will never result in ethical behavior; "Ethical 
witnessing is a revelation that is not [a matter of] knowledge" (cited in Casey 2003, 189). According to Levinas, ethics consist precisely in our responsiveness to the singularity of the existent which is neglected in knowledge, i.e. the 'face' of another person. From a Levinassian perspective, therefore, we can argue that the gap between ethical judgement and ethical behavior cannot be bridged by the enhancement of knowledge and rational choice; only the singularity of the face of another person can call us to act in an ethical way.

Does Levinas provide a model for appropriate ethical behavior in response to the ecological crisis we face today? Building on Levinas's thought, Casey (2003) tried to develop a phenomenological environmental ethics. To this end, he first of all extended the concept of the face, which was originally restricted to persons, to the environment as a whole; it is the singularity of the sur-face of the environment which according to Casey calls us to act in an ethical way. ${ }^{1}$ Secondly, he introduced the human glance of distress at the environmental surface as a necessary condition for ethical action:

An ethics of the environment must begin with the sheer and simple fact of being struck by something wrong happening in the surrounding world. It is by noticing that something is out of joint-does not fit or function well-that a response is elicited and an action induced. Responsive action begins with what John Dewey called the "problematic situation". Unless this situation is apprehended in its very problematicity, it will remain noxious, troublesome, harmful. People will go on being persecuted and tortured, chemicals will circulate freely in the air, and food and water will be poisoned-unless attention is given to what is awry in these circumstances. ... My claim is that the human glance, meagre as it seems to be, is indispensable for consequential ethical action (Casey 2003, 187-188).

In order to make his case, Casey refers to the affordance theory of the American psychologist and founding father of ecological psychology, James Gibson. Gibson argued that the surface or layout of the environment 'affords' specific behavior for

\footnotetext{
1 Although Levinas may inspire environmental philosophers to extend the face of the Other to the surface of the environment, it is clear that Levinas himself would reject such an extension. He not only limits the concept of the face explicitly to the face of human beings-animals do not have a face-but he also rejects any direct ethical obligation to nature: "Pure nature, when it does not attest to the glory of God, when it is no one's, indifferent and inhuman nature, is situated on the fringes of this human world, and is only understandable as such on the plane of the human world of property" (Levinas 1987: 28-29). Only in the context of our ethical obligations toward the other (human beings) does nature have a function to provide food, shelter etc. But according to Levinas nature as such is opposed to ethics. The reason is that nature is characterized by the Darwinian struggle for existence, i.e. the "natural will to put my own existence first", while ethics on the contrary consists in our submission to the Other (cf. Nelson 2012: 109-133). In this respect, the infinity of the face of the Other and the infinity of nature are incomparable (cf. Toadvine 2012: 164-165); a Levinassian ethics of the environment can therefore not be derived from and justified by an appeal to nature (Nelson 2012: 120). In his insightful article, Toadvine therefore concludes: “. . . to be ethical first of all requires turning one's back on the struggle for existence that characterizes the natural world and animal life. It is this sense of nature that is at stake in Levinas's insistence that ethics is a gratuitous 'rupture with nature'. Adopting this view on nature, Levinas's ethics may in fact pose the greatest challenge to any future environmental philosophy that would recognize obligations toward nature as such" (Toadvine 2012: 179). In this respect, Levinas's thought cannot be taken as a kind of proto-environmentalism, as Casey seems to do.
} 
animals in the environment (see "Affordance and Behavior" section for a discussion of the concept of affordance). Inspired by Gibson, Casey claims that the phenomenological human glance of environmental distress is the source of the compelling power to act ethically; environmental distress motivates or 'affords' us "to alter the disturbed circumstance: to "set it right", (Casey 2003, 204). ${ }^{2}$ Following Levinas, Casey rejects 'knowledge' and stresses the sur-face of the environment as the origin of our ethical and pro-environmental behavior. In fact, he replaces knowledge of the environment by the phenomenological human glance of the environment to prevent the akrasia that manifests itself in the gap between our ethical judgments about the ecological crisis and our ethical behavior according to this judgment. In the human glance of environmental distress, we are immediately called or 'afforded' to act pro-environmentally (Casey 2003, 203).

One can argue, however, that Casey didn't solve the problem of akrasia because the human glance of the ecological crisis doesn't lead automatically to more proenvironmental behavior. Also Casey himself had to admit that there are masses of people who do not respond to the experience of environmental distress. This means that in the end, the human glance of environmental distress is insufficient to encourage more pro-environmental behavior.

According to Casey, this 'failure' to respond to the affordances in the environment is due to "the detached Cartesian eye that bespeaks a massive cultural disconnect between human beings and their environments" (Casey 2003, 205). Human being is understood here as apart from nature and consists in the will to master and exploit the natural world as a commodity for human needs. This humanas-apart-from-nature attitude of modern mankind is characterized by a fundamental dualism between humankind and nature, whereby humans create and project values onto an in itself valueless world, i.e. humanity is the Cartesian mâitre et possesseur de la nature. What this human-as-apart-from-nature attitude fails to see, according to Casey, is our lived connectedness with the world around us. ${ }^{3}$ Our ethical responsiveness toward the ecological crisis therefore not only presupposes the human glance of the affordances in the environment but also a conceptualizing of human existence as interconnected with the environment; a human-as-a-part-ofnature attitude which is characterized by non-dualism, non-anthropocentrism and eco-centrism. As long as the human-as-apart-from-nature attitude is dominant in our society, the human glance of environmental distress is insufficient to bridge the gap between our ethical judgments about the ecological crisis and our ethical behavior according to these judgments.

\footnotetext{
${ }^{2}$ Humphrey (2000) has shown that such a seemingly automatic link between 'perception' and 'action' makes moral freedom of action problematic.

${ }^{3}$ In this, Casey's position resembles that of the deep ecologists, who called for a new understanding of what humanity and nature are in itself (non-dualistic, non-anthropocentric and eco-centric). We have to move away from the traditional humans-apart-from-nature attitude toward one that sees humans-as-apart-of-nature according to the deep ecologists. Naess for instance rejects "the total man-in-environment image in favour of the relational total-field image. Organisms as knots in the bio spherical net or field of intrinsic relations. An intrinsic relation between two things $\mathrm{A}$ and $\mathrm{B}$ is such that the relation belongs to the definition or basic constitution of A and B, so that without the relation, A and B would no longer be the same things" (Naess 1973; cf. Marietta 1995).
} 
What Casey failed to notice in his reading of Gibson's work is, however, that an affordance in the environment in itself calls for and is accompanied by actual behavior. This means that a gap between ethical judgments and ethical behavior could be bridged by an affordance of nature. In this article, we revisit the affordance theory of Gibson in order to bridge the gap between ethical judgment and ethical behavior in the current ecological crisis. There are two specific reasons to consult Gibson's work in this respect: First of all, Gibson provides a concept of human existence as interconnected with the environment that is characterized by nondualism, non-anthropocentrism and eco-centrism. Secondly, this concept of the interconnectedness of human existence and the environment is conceptualized in such a way that the environment really 'affords' action and behavior. In this article, we first explore Gibson's affordance theory in order to bridge the gap between ethical judgment and ethical behavior with regard to the current ecological crisis (see "Affordance and Behavior" section). Based on the current discussion of the affordance of nature, we open a radically new perspective on the current ecological crisis and the nature of our ethical judgments with regard to this crisis (see "Analysis: The Affordance of Nature in the Age of Management" section). In "Conclusion: The Affordance of Ecological Awareness" section we reflect on the implications of this analysis for our actual behavior in response to the ecological crisis, and draw some conclusions.

\section{Affordance and Behavior}

\section{The Affordance Theory of James Gibson ${ }^{4}$}

According to James Gibson, one of the most influential psychologists in the field of visual perception in the twentieth century, we do not perceive stimulus information from the outside world, which we then process consciously or unconsciously, but we perceive affordances in the environment. The word "affordance" indicates the meaning of a thing or organism in the environment, which is detected or picked up by the perceiver and allows him to perform a specific kind of action; air affords breathing and water affords drinking for example, a chair affords sitting and a hammer affords hammering. According to Gibson, "the affordance of anything is a specific combination of the properties of its substance and its surfaces taken with reference to an animal" (Gibson 1977, 67). If a substance is rigid, horizontal and extended for instance, then it affords support; it is the ground or floor we are walking on.

Not only the physical environment, but also other animals harbour affordances according to Gibson. Their sexual, predatory, nurturing, fighting, cooperating and communicating interactions for instance harbour a complex set of affordances: A beautiful butterfly, for example, affords its predator to hunt for it. Although the butterfly affords hunting, this doesn't mean that the meaning of the butterfly for the

\footnotetext{
${ }^{4}$ Parts of this section were published already in Blok (2014). See there for a more in-depth analysis of Gibson's affordance ontology.
} 
predator is a characteristic of the butterfly. The affordance is taken with reference to an animal: a rigid and horizontal surface affords support for the predator for instance, but not for fish. In the same way, air affords flying for butterflies but not for a cat as their predator. This relativity of the affordance doesn't mean that the meaning of the butterfly depends on the valuation of this object by the subject. In the case of inanimate objects, affordances stem from the environment, and in the case of animate objects, affordances come up in the reciprocity of animals and other animals. Gibson provides the example of a mother and her child and a prey and its predator: What the child affords the mother is reciprocal to what the mother affords the child and what the prey affords the predator-hunting-is reciprocal to what the predator affords the prey-hiding. In this respect, we already have to nuance Casey's idea that the affordance is a property of the surface of the environment, which affords ethical behavior. In fact, the affordance points two ways and therefore cannot be understood as a property of the surface of the environment as Casey thought (i.e. a property of an object) nor as the product of the human glance (property of the subject).

As I have argued elsewhere, we have to conceive affordances at an ontological level (cf. Blok 2014). This means that the predator for instance does not first see the prey and then takes action. On the contrary, prey and predator are constituted by their mutual affordances; in the mutual affordances of prey and predator, the prey affords hunting and the predator affords hiding, and in their actual behaviour in response to the affordance their identities as prey and as predator are performatively constituted; in their mutual affordance, the prey becomes the one hiding from the predator and looking for shelter in holes and caves, while the predator becomes the one hunting for the prey. With this, it becomes clear how the affordance has to be understood. The affordance is the (non-subjective) meaning of the prey and the predator. This sense or meaning comes up in the reciprocity between prey and predator; both butterfly and predator live already in a meaningful world in which they are what they are, i.e. perform hiding and seeking. The ontological status of the affordance is that it articulates a meaningful world (eco-system) for an organism and allows it to perform its specific behavior as prey, as predator etc.

How do we have to conceive the concept of nature from a Gibsonian perspective $^{5}$ ? To explain the reciprocity of animal and environment, Gibson makes use of the ecological concept of a niche. A niche can be seen as a set of environmental features which are suitable for a specific species and into which this species fits (Gibson 1977, 69). It concerns the natural environment, which is understood in a non-dualistic and non-anthropocentric way. Gibson would agree with Casey that humankind is interconnected with the environment (see "Introduction"). Both organisms like humans and the natural environment are constituted by their reciprocity, for instance the mutual supportive realities of the environment (materials for making a house) and a human being which settles itself in this

\footnotetext{
5 It is clear that Gibson's primary goal was to develop an ecological physics and that he was not interested in the development of a concept of nature. Nevertheless, there is no reason in principle why his analysis of the affordance cannot be applied at the level of specific eco-systems - Kadar and Effken (1994) developed for instance such a regional ontology — and at the level of the eco-system of the earth or nature as a whole-Sanders (1997) for instance developed such a general ontology (Sanders 1997, 108).
} 
environment to build his house. "We all fit into the substructures of the environment in our various ways for we were all, in fact, formed by them. We were created by the world we live in" (Gibson 1977, 71). Furthermore, this Gibsonian concept of nature is eco-centric: "The reciprocity of animal and environment is implied by this theory for the niche implies a certain kind of animal and the species implies a special niche. But the independent existence of an unlimited environment is also implied, for the niches must be available before animals can begin to exploit them. The affording of life by the environment is presumably of unlimited richness and complexity" (Gibson 1977, 69).

The eco-centrism of a Gibsonian concept of nature shows itself not only in the concept of the niche, in which all animal behavior is understood as responsive behavior in response to affordances in the environment and in this way is interrelated. It shows itself also in the fact that the "independent existence of an unlimited environment" (Gibson 1977, 69) is assumed. That means that besides the actual occupation of a niche by an animal, the environment provides possibilities for action that have not been taken advantage of; the possible sense or meaning of nature is always beyond the actual meaning of the world we live in. In this sense, nature is limitless according to Gibson. We encounter here a second meaning of nature, besides the concept of the niche where there is a mutual reciprocity of the environment and human existence; nature as the unlimited domain of possible affordances. Although Gibson himself didn't explore the relation between nature as niche and nature as an "unlimited richness and complexity" of the environment, we can conceptualize this concept of nature as the material domain or substrate where possible affordances originate from and actual affordances go back to. ${ }^{6}$

\section{The Affordance of (Ethical) Behavior}

With our ontological reading of Gibson's affordance theory, we encounter a concept of human existence as interconnected with nature, and which is characterized by non-dualism, non-anthropocentrism and eco-centrism. Is it possible to conceptualize this interconnectedness of human existence and nature in such a way that the environment really affords ethical behavior? Our Gibsonian concept of the interconnectedness of human existence and the environment is promising in this respect, because affordances in the environment call for certain action and behavior; the prey affords the activity of hunting for the predator and vice versa. Does our Gibsonian concept of the interconnectedness of human existence and nature serve our objective in this article to bridge the gap between ethical judgment and ethical behavior?

To understand the relation between the meaningful eco-system organisms live in and its call for action and behavior, we focus for a moment on Gibson's discussion with one of his predecessors, the gestalt psychologist Koffka (1886-1941). According to the gestalt psychologists, the meaning of an object is perceived just as immediately as its size or color. This meaning of an organism is not a neutral

\footnotetext{
6 The question whether the affordances of nature are the product of a generative power of this materiality, for instance the product of 'vibrant matter', is beyond the scope of this article (cf. Bennett 2010).
} 
quality of an object in front of us, but is something demanding immediate action: "Man behaves in a situation as the situation tells him to behave... Each thing says what it is... a fruit says, "Eat me"; water says, "Drink me"; thunder says, "Fear me"; and woman says, "Love me" (Koffka 1935, 7). Fruit and water "tell us what to do with them" (Koffka 1935, 353), they demand us to eat them or to drink them. Thus, our understanding of the meaning of an organism not only underlies our practical dealing with these organisms, but this meaning directly invites or demands specific behavior: eating, loving etc.

While Koffka argued that this demand-character of the meaning of an observed object varies with the need of the observer-a post-box for instance has only demand character for us when we need to mail a letter-Gibson draws another conclusion. Because the observer and that which is observed are constituted by their mutual reciprocity and not the other way around, the constituent (the affordance) cannot change as the need for that which is constituted changes, i.e. the post-box for a letter-mailing human being. "I prefer to say that the real post-box ... affords lettermailing to a letter-writing human in a community with a postal system. This fact is perceived when the post-box is identified as such, and it is apprehended whether the post-box is in sight or out of sight. To feel a special attraction to it when one has a letter to mail is not surprising but the main fact is that it is perceived as part of the environment - as an item of the neighborhood in which we live. Everyone above the age of six knows what it is for and where the nearest one is" (Gibson 1977, 78).

This mutual reciprocity constitutes a meaningful world (eco-system) in which post-boxes are 'on the corner' for 'love- or application letter' writing humans or people who have to 'announce a marriage or the death of someone' and so on; both the post-box and the letter writing human being exist in a meaningful world in which they are what they are and act accordingly. For Gibson therefore, the sense or meaning is not restricted to an individual organism, but concerns the whole of a meaningful world in which human beings and post-boxes are at home. This meaningful world of letters and post-boxes (ontic level) is first of all constituted by their mutual reciprocity (ontological level), in which the post-box becomes post-box for 'love- or application letter' writing humans. Secondly, the demand-character cannot be separated from the meaning-character of the affordance: "The theory of affordances implies that to see things is to see how to get about among them and what to do or not to do with them" (Gibson 1979, 223). Just as the prey becomes the one hiding from the predator in the mutual reciprocity between prey and predator, a human being becomes the one who is actually writing and sending letters in the mutual reciprocity between post-box and human being. ${ }^{7}$ The constitution of a meaningful world in which human being appears as sender and receiver of mail is the 'main fact' (ontological level), not the 'special attraction' to the post-box on the ontic level.

With the elaboration of the intrinsic relation between the meaning-character and the demand-character of the affordance, we not only encounter a concept of human

\footnotetext{
${ }^{7}$ I agree with Sanders's analysis that the affordance to write a letter doesn't have to be complemented or effectuated by our intention to write such a letter. Intention is vital in perception, but is already implicit in the idea of affordance (Sanders 1997, 105).
} 
existence as interconnected with nature, but this interconnectedness consists in our responsiveness to the affordances of nature. If nowadays we face a gap between our ethical judgments about the ecological crisis and our actual ethical behavior according to these judgments, the question arises whether an affordance of nature could bridge this gap. Our Gibsonian concept of human existence as interconnected with nature is at least promising in this respect, because affordances call for action and behavior for organisms which are able to notice them. In the next section, therefore, we ask whether an affordance of nature could lead to more ethical behavior.

\section{Analysis: The Affordance of Nature in the Age of Management}

If we look at the current ecological crisis, we face a growing and threatening ecological catastrophe. Climate change, loss of biodiversity, desertification, poisoned seas and agricultural land, all these phenomena show the way we currently harm our planet. According to Casey, our 'failure' to be responsive to environmental distress is due to our humans-as-apart-from-nature attitude (see introduction). While the human-as-apart-from-nature attitude of human being is blind to the affordances of nature, the human-as-a-part-of-nature attitude is in fact afforded to perform ethical behavior, according to Casey.

In the previous section, we developed such a concept of human existence which is interconnected with nature, based on the work of James Gibson. This concept is promising in two respects; first of all, the affordance ontology provides a nondualist, non-anthropocentric and eco-centrist concept of human existence as-a-partof-nature. Secondly, the affordance ontology provides a concept of human existence which is primarily responsive to the affordances of nature. But if we take this concept of the interconnectedness of human existence and nature into consideration, we have to draw a radically different conclusion than Casey.

If the concept of the affordance provides us with a concept of human existence which is interconnected with nature and is characterized by non-anthropocentrism, we cannot blame a specific human attitude for "missing the message" of nature, as Casey suggests (Casey 2003, 205). The interconnectedness of human existence and nature first of all prevents us from blaming unsustainable behavior on human beings as one of the actors involved in this interrelation. ${ }^{8}$ In fact, if human existence and nature are both constituted by their mutual reciprocity and act accordingly, 'we' are not the primary subject of the decision to exhibit a specific kind of responsiveness to the affordances of nature. In this respect does Casey's position still contain a hidden form of anthropocentrism.

Secondly, we cannot even distinguish anymore between a human attitude which is blind to the affordances of nature and a human attitude which is really afforded to perform ethical behavior. If nature and human existence are both constituted by

\footnotetext{
${ }^{8}$ The hesitation to identify human existence as a single cause or causa efficiens of the ecological crisis in case human existence is understood as interconnected with nature, is also acknowledged by other authors (cf. Bennett 2010).
} 
their mutual reciprocity and act accordingly, all human behavior has to be understood as responsive action in response to the affordances of nature. Just as the prey becomes the one hiding from the predator in the mutual reciprocity between prey and predator, the human being becomes the one acting according to the affordances of nature ${ }^{9}$; the first conclusion we have to draw, therefore, is that all human behavior is already responsive to the affordances of nature, the human-asapart-from-nature attitude no less than the human-as-a-part-of-nature attitude.

This conclusion seems at first sight to be counter-intuitive. According to a critical reader, there is still a world of difference between a human being who is motivated to 'alter the disturbed circumstances' and displays behavior aimed at conserving natural resources, and a human being who is 'blind' to the ecological crisis and goes on with the depletion of the natural resources of the earth. The differentiation between a human-as-apart-from-nature and a human-as-a-part-of-nature attitude seems to be highly relevant with respect to the current ecological crisis.

And yet, as Ladelle McWhorter has pointed out, both nature destroying and nature conserving behavior can be characterized by the word management.

Today, on all sides of the ecological debate, we hear, with greater and greater frequency, the word management. On the one hand, business people want to manage natural resources so as to keep up profits. On the other hand, conservationists want to manage natural resources so that there will be plenty of coal and oil and grizzly bears and recreational facilities for future generations to use and enjoy. These groups, and factions within them, debate vociferously over which management policies are the best-that is, the most cost-efficient and manageable. Radical environmentalists damn both groups and contend that it is human population growth, resource consumption, and rising expectations that are in need of management. But wherever we look, wherever we listen, we see and hear the term management (McWhorter 2009, 9).

Although there seems to be a world of difference between a depleting and a conserving human attitude toward natural resources, they are essentially the same; the sense or meaning of human being on the ontological level, namely as manager of human and natural resources, is the main fact, not specific behavior such as nature conserving or nature destroying behavior.

This means, first of all, that the depleting attitude is not blind to the affordances in the environment as Casey suggests, because this managerial behavior is just as responsive to the affordances of nature as the conserving attitude. This means, secondly, that the depleting attitude is not a human-as-apart-from-nature attitude, because this attitude is just as the human-as-a-part-of-nature attitude constituted by the mutual reciprocity between men and nature, and therefore is a-part-of-nature. This means, thirdly, that we are not in need of a new conceptualization of human existence as interconnected with the environment, as Casey suggests; all human behavior is already constituted by the mutual reciprocity between human existence

\footnotetext{
9 Harry Heft already argued that the affordance includes the requisite intentional aspects of our response to the affordance of nature (cf. Heft 1989; cf. Sanders 1997).
} 
and the environment and therefore, already responsive to the affordances of nature. We therefore have to reject Casey's idea that the 'failure' to respond to the affordances of nature is due to a humans-as-apart-from-nature attitude; not only our judgment (knowledge) about the ecological crisis is an insufficient condition for the accomplishment of more ethical and pro-environmental behavior, but the same holds true for a human-as-a-part-of-nature attitude of human existence.

What then could explain the persistence of the gap between our ethical judgments about the ecological crisis and our ethical behavior according to these judgments, given the fact that the human glance of environmental distress cannot be missed anymore in our society? We have to draw a negative conclusion first, namely that in our current society, no such thing can be found as an affordance to 'set things right', based on the human glance of environmental distress. ${ }^{10}$ In fact, the depleting attitude itself is due to affordances of nature. In the current age, we are not or not primarily afforded to 'alter the disturbed circumstance' as Casey suggests, but to manage the human and natural resources of our planet. It is this affordance of nature to manage human and natural resources which explains the gap between our ethical judgments with regard to the ecological crisis and our ethical behavior according to these judgments.

'We' cannot even be held 'responsible' for this gap. Such a position contains the anthropocentric gesture that 'we' have to 'set things right' and fails to see the interconnectedness between human existence and nature, misses the mutual reciprocity between the affordances of nature and our responsiveness to these affordances. And if we take the eco-centrism of this mutuality into account, we have to draw an even more radical conclusion, namely that nature herself is 'responsible' for the destruction of the planet. Why? If both eco-system depleting and destroying management practices are responsive to affordances of nature, this responsiveness is grounded in the mutual reciprocity between human existence and nature. And if this mutuality has to be understood in an eco-centric way, then the destruction of the planet is initiated by an affordance of nature herself. The affordance ontology therefore opens a new perspective on the current ecological crisis: to the extent that the destruction of the environment is responsive to an affordance of nature, this destruction can be seen as the self-destruction of nature. ${ }^{11}$ This new perspective on the current ecological crisis is the price we have to pay for a concept of human existence as primarily responsive to the affordances of nature.

\section{Conclusion: The Affordance of Ecological Awareness}

In the previous section, we have seen that human existence is always responsive to affordances of nature, both the natural resources conserving attitude and the natural resources depleting attitude, and that the destruction of planet earth is initiated by an

\footnotetext{
${ }^{10}$ In this, I follow authors like Bruno Latour who admit that the inspiration of nature to live an ecological life is still present in our society, but in decline under the pressure of the technologization of our relation with nature.

${ }^{11}$ See Reza Negarestani's novel Cyclonopedia for a fictional exploration of this idea of the selfdestruction of nature.
} 
affordance of nature herself. At the same time, the ecological crisis confronts us with an absolute limit of the carrying capacity of the ecosystems of planet earth, and the experience that it cannot continue like this. Sloterdijk (2009) even speaks of a new imperative due to the environmental distress we are confronted with ${ }^{12}$ : you have to change your life. Where do we find the affordance to change our life, and to what extent is this changed way of life different from the management of natural and human resources?

Our responsiveness to the affordances of nature doesn't mean that human existence is completely passive with regard to the affordances of nature, and that people are forced to contribute to the management of human and natural resources. As we have seen in section one, the eco-centrism of the affordance ontology not only means that human existence is responsive to actual affordances of nature. Besides the actual occupation of a niche by our responsiveness to the affordances of nature, the environment provides possibilities for action that have not been taken advantage of. Is it possible to ground our pro-environmental behavior on possibilities for action, instead of on actual affordances provided by the environment?

Casey's environmentalism can be considered responsive to actual affordances of nature. It consists in the decision to alter the disturbed circumstances and to take care of the non-human environment, and is embedded in an anthropocentric human ethos to manage human and natural resources. But it is not necessary to live and act on earth as a manager of human and natural resources. Our discussion of the affordance ontology in this article opens precisely a possibility for action that has not been taken advantage of till now; the affordance ontology displaces human being from the center (non-anthropocentrism) and articulates our human responsiveness to the affordances of nature (eco-centrism). Furthermore, the affordance ontology bridges the fundamental division between human existence and the (nonhuman) environment in favor of the interconnectedness and mutual reciprocity of our conjoint action and behavior. This non-dualist, non-anthropocentric and ecocentric conceptualization of our human responsiveness to the affordances of nature opens a perspective on human action and behavior as interconnected with and responsive to the affordances of nature. As a consequence, 'we' are not primarily responsible for taking care of planet earth; this involves a conjoint action of human and non-human agents that build the eco-systems of planet earth. In this respect, the affordance ontology opens a perspective on human existence that is no longer living on earth but living as earth (cf. Bennett 2010). Contrary to a human ethos that consists in the management of human and natural resources in order to protect the non-human environment, the affordance ontology opens the possibility of a human ethos that consists in the engagement with nature as the material domain that both humans and the non-human environment are part of, and which is the substrate where possible affordances originate from and actual affordances go back to. Can

\footnotetext{
12 Cf. "Yet as is the case with any disposition, distress propels the self as "thrown" into the forefront of a situation, in such a way as to call attention to its furthest margins where the contours of the ethos first arise. By experiencing distress, human beings enter the breach of a crisis, in which all of the variables that comprise the frailty of human existence-ambiguity, conflict, accident-become most pronounced" (Schalow 2006, 73).
} 
the affordance ontology be seen as an affordance to change our life, which no longer consist in our living on earth but in our living as earth?

The distinction between actual and possible affordances of nature enables us to acknowledge the actual fit between nature as resource and human being as the manager of these resources in the age of management, and to keep open the possibility in principle of another affordance of nature at the same time; the nondualist, non-anthropocentric and eco-centric engagement with nature and as nature. Although humanity will not easily give up its special position as manager of planet earth, it is this anthropocentric gesture that we have to abandon in favor of an emerging ecological awareness of the interconnectedness and interdependency of human and non-human actors in the environment (cf. Morton 2013). What is the role of human action and behavior in this transition to this ecological awareness?

If we take the interconnectedness and conjoint action of human and non-human actors seriously, the transition from human existence as manager to an eco-centric concept of human existence is not dependent on our knowledge or on our human-asa-part-of-nature attitude, but primarily on the emergence of another affordance of nature itself. According to philosophers like Morton, 'hyperobjects' like global warming compel us to think ecologically (Morton 2013, 48). On the one hand, the hegemony of human existence as manager of natural and human resources in our society may be seen as an indication that we are possibly waiting for an affordance that still has to come. On the other hand, if we take the interconnectedness and conjoint action of human and non-human actors seriously, the emergence of such an affordance of nature presupposes our actual responsiveness to this possible affordance of nature as well; the affordance, as we have seen, involves action and behavior, and this means that a new affordance of nature in fact only lies in our actual responsiveness to this possible affordance. This means that we have to explore and experiment with a non-dualist, non-anthropocentric and eco-centric concept of our human responsiveness to the affordances of nature, i.e. to experiment with the rejection of our living on earth and the acceptance of our living and acting as earth. And here, our responsibility in the age of management becomes clear. In the wake of Casey's call for the human glance, we could argue that the human glance precisely concerns the phenomenological sensitivity to the possible affordances of nature beyond the actual affordances in the age of management, and consists in the experimentation with this non-dualist, non-anthropocentric and eco-centric concept of our human responsiveness to the affordances of nature, i.e. the experimentation with the conjoint action of human and non-human actors in order to make this transition from our living on earth to our living as earth happen.

Acknowledgments I would like to thank the reviewers of JAEE for their valuable comments on an earlier draft of this article.

Open Access This article is distributed under the terms of the Creative Commons Attribution 4.0 International License (http://creativecommons.org/licenses/by/4.0/), which permits unrestricted use, distribution, and reproduction in any medium, provided you give appropriate credit to the original author(s) and the source, provide a link to the Creative Commons license, and indicate if changes were made. 


\section{References}

Aristotle, (1990). Nichomachean ethics. Cambridge/London: Harvard UP.

Bennett, J. (2010). Vibrant matter. A political ecology of things. Durham and London: Duke University Press.

Blok, V. (2014). Reconnecting with nature in the age of technology: The heidegger and radical environmentalism debate revisited. Environmental Philosophy, 11(2), 307-332.

Casey, E. S. (2003). Taking a glance at the environment: Preliminary thoughts on a promising topic. In T. Toadvine \& C. S. Brown (Eds.), Eco-phenomenology. Back to the earth itself (pp. 187-210). Albany: State of New York Press.

Friends of the Earth. (2009). Overconsumption. Our use of the world's natural resources. Amsterdam: Friends of the Earth.

Gibson, J. (1977). The theory of affordances. In R. Shaw \& J. Bransford (Eds.), Perceiving, acting and knowing. Hillsdale/New Jersey: LEA.

Gibson, J. (1979). The ecological approach to visual perception. Boston: Houghton Mifflin Company.

Heft, H. (1989). Affordances and the body: An intentional analysis of Gibson's 'ecological approach to visual perception'. Journal for the Theory of Social Behavior, 19, 1-30.

Humphrey, M. (2000). Ontological determinism and deep ecology: Evading the moral question? In E. Katz, A. Light, \& D. Rothenberg (Eds.), Beneath the surface: Critical essays in the philosophy of deep ecology (pp. 85-106). Cambridge: MIT Press.

Kadar, E., Effken, J. (1994) Heideggerian meditations on an alternative ontology for ecological psychology: A response to Turvey's (1992) proposal. Ecological Psychology, 6(4), 297-341.

Koffka, K. (1935). Principles of Gestalt psychology. London: Routledge \& Kegan Paul Ltd.

Levinas, E. (1969). Totality and infinity. Pittsburgh: Duquesne UP.

Levinas, E. (1987). Collected philosophical papers. Pittsburgh: Duquesne UP.

Marietta, D. E, Jr. (1995). For people and the planet. Philadelphia: Temple University Press.

McWhorter, L. (2009). Guilt as management technology. In L. McWhorter \& G. Stenstad (Eds.), Heidegger \& the earth. Essays in environmental philosophy (2nd ed.). Toronto/Buffalo/London: University of Toronto Press.

Morton, T. (2013). Hyperobjects. Philosophy and ecology after the end of the world. Minneapolis: University of Minnesota Press.

Naess, A. (1973). The shallow and the deep, long-range ecological movement. Inquiry, 16, 95-100.

Nelson, E. S. (2012). Levinas and Adorno. Can there be an ethics of nature? In W. Edelglass, J. Hatley, \& C. Diehm (Eds.), Facing nature. Levinas and environmental thought (pp. 109-133). Pittsburgh: Duquesne.

PBL Netherlands Environmental Assessment Agency. (2013). Trends in global CO2 emissions: 2013 report. The Hague: PBL.

Sanders, J. T. (1997). An ontology of affordances. Ecological Psychology, 9(10), 97-112.

Schalow, F. (2006). The incarnality of being: The earth, animals, and the body in heidegger's thought. New York: State University of New York Press.

Sloterdijk, P. (2009). Du must dein Leben ändern. Frankfurt a.M: Suhrkamp.

Toadvine, T. (2012). Enjoyment and its discontents. On separation from nature in Levinas. In W. Edelglass, J. Hatley, \& C. Diehm (Eds.), Facing nature. Levinas and environmental thought (pp. 161-189). Pittsburgh: Duquesne.

WWF. (2012). Living planet report 2012. Gland: WWF. 